\title{
Control of Indoor Swimming Pools with Potential for Demand Response
}

\author{
Eliseu Manuel Artilheiro Ribeiro ${ }^{1,2}$, Humberto Manuel Matos Jorge ${ }^{2,3}$ and Divo Augusto Alegria Quintela ${ }^{4,5}$ \\ 1. School of Technology and Management, Polytechnic Institute of Leiria, Leiria 2411-901, Portugal \\ 2. INESCC (Institute for Systems and Computers Engineering of Coimbra), Coimbra 3000-033, Portugal \\ 3. Department of Mechanical Engineering, University of Coimbra, Coimbra 3030-790, Portugal \\ 4. Department of Electrical Engineering and Computers, University of Coimbra, Coimbra 3030-790, Portugal \\ 5. ADAI (Association for the Development of Industrial Aerodynamics), Coimbra 3031-289, Portugal
}

Received: May 21, 2013 / Accepted: July 31, 2013 / Published: January 31, 2014.

\begin{abstract}
Buildings with indoor swimming pools are recognized as very high-energy consumers and present a great potential for electrical and thermal energy savings. A BEMS (building energy management system) could be conceived in order to optimize the building energy demand and with smart grid interaction. This paper presents the condition and potential contract-based demand side response in indoor swimming pools context. The BEMS designed by the authors implements control strategies for HVAC (heating, ventilation and air conditioning) and pumping system in order to reduce the electricity demand during peak hours or in response to an emergency signal from the system operator in critical times. The control strategies for HVAC was carried out by Building Thermal Simulation and the used of a theoretical formula for pumping system, strategies can carry out a significant reduction in power demand both in HVAC and pumping systems.
\end{abstract}

Key words: Indoor swimming pools, building energy management system, smart grid, demand response.

\section{Introduction}

In Portugal, the number of sport complexes with ISP (indoor swimming pools), with an intensive use, has increased significantly during the last decades. The growing of such facilities has shown the necessity to promote the evaluation and control of the indoor environment variables in order to minimize the energy consumption, according to the measures proposed by the European Community Directive 2006/32/EC [1]. By this directive, all buildings must be classified from an energy point of view, using the EEI (Energy Efficiency Index), have to implement measures leading to the RUE (rational use of energy), and install a BEMS

Corresponding author: Eliseu Manuel Artilheiro Ribeiro, professor, research fields: building thermal performance, rational use of energy in buildings, building energy management system and industrial automation. E-mail: eliseu.ribeiro@ipleiria.pt. (building energy management system).

Energy evaluation studies of an ISP are matters of recognized complexity since quite distinct and broad fields of knowledge are required. On the other hand, most of the available contributions are very specific. The energy demand of the conventional ventilation technique in indoor swimming pools has been compared to two different heat-recovery techniques, the mechanical heat pump and the open absorption system [2]. The open absorption system is a new technique in this application. Calculations have been carried out on an hourly basis for the different techniques. Measurements from an absorption system pilot-plant installed in an indoor swimming pool in the northern part of Sweden have been used in the calculations. The results show that with the mechanical heat pump, the electrical input increases by 63 MWh/year and with the open absorption system, 57 
MWh/year. However, a mechanical heat-pump and an open absorption system decrease the annual energy demand from $611 \mathrm{MWh}$ to $528 \mathrm{MWh}$ and $484 \mathrm{MWh}$, respectively [3].

The evaluation of the thermal performance and life cycle energy cost of using heat pumps for hotel swimming pools in subtropical climates has been made the object of analysis [4].

In the case of indoor swimming pool facilities, a large amount of energy is required to heat up low-temperature outdoor air, before it is introduced indoors to maintain indoor humidity. Since water evaporates from the pool surface, the exhausted air contains more water and specific enthalpy. As a consequence of this indoor air, the heat pump is generally used in heat recovery in indoor swimming pools. It reduces possible energy consumption costs using a particle swarm algorithm to develop an optimization model for the design of a heat pump system in the indoor swimming pool with life cycle energy costs as the objective function [5].

A BEMS was designed to integrate some control strategies in order to optimize the building energy demand, sent able to reduce electric energy consumption during peak periods or in response to an emergency signal by the utility requesting power demand reduction.

There are some roles and responsibilities of actors involved in the SG (smart grids) deployment, defined by the European Community task force for SG [6]. The focus of these roles is the DR (demand response). Developments in DR vary substantially across Europe reflects national conditions and are triggered by different sets of policies, programs and implementation schemes [7]. Currently in Portugal, the electricity pricing relies on TOU (time of use) tariffs that penalize the consumption of electricity in the peak periods.

In addition to control strategies for reducing power demand the full study also deals with the optimal use of energy in all main ISP process: HVAC (heating, ventilation and air conditioning) system, PS (pumping system), water heating for baths and lighting.

\section{Methodology}

The DR essence is to manage customer electricity consumption in response to supply conditions, for example: reduce consumption at CT (critical times) or in RMP (response to market prices).

The first topic (CT) normally occurs in short periods of time when it is necessary flexibility of power consumption at the client's side to allow supplier selection. For this situation, it is required that the supply contract allows the reduction of energy consumption to the consumer.

The second topic (RMP) is used in longer periods of time, during the peak hours where the price of energy is higher. In the near future, the utilities will offer real time pricing tariffs, where the peak hours are dynamic, not fixed.

Subsequently, there are defined the conditions that the consumer can reduce energy bills, but for that he should have the capacity to reduce power demand in the process without exceeding the minimum threshold of safety or comfort.

In ISP can by identify three main energy processes [8] that are responsible for almost $90 \%$ of the overall electric energy consumption (Fig. 1).

The HVAC and PS could have greater potential to reduce electricity consumption, but it must be guaranteed certain conditions related to the level of water quality and comfort.

For HVAC the environmental conditions of ISP are regulated by the standard NP EN 15288-1 [9], where it is defined besides other parameters that $\mathrm{RH}$ (relative humidity) could change between $40 \%$ and $80 \%$,

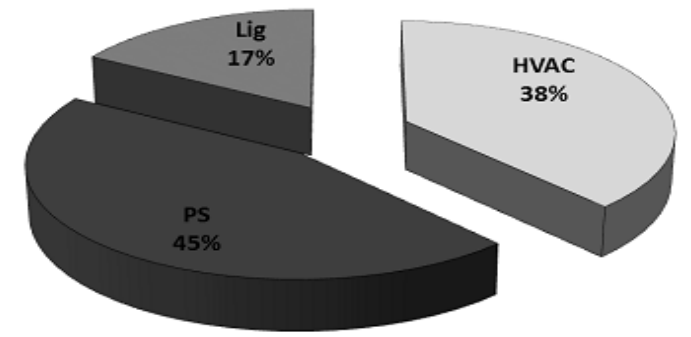

Fig. 1 Electric energy consumption by topic. 
preferably less than $60 \%$.

In CT case, the environmental variable threshold for RH could be adjusted to achieve $80 \%$ for a maximum period of 30 minutes so that to have no excessive degradation of the environmental conditions. After period of control the environmental threshold must be going back to the normal value.

In RMP case, the environmental threshold should be adjusted with $\mathrm{RH}$ to reach $60 \%$ as long as people want.

In the PS, the control conditions are strongly dependent on the quality of water determined by the Langelier index [10, 11] also known as SI (saturation index). In these cases, the SI is considered satisfactory when it remains between -0.5 and $+0.5[12,13]$.

During the CT case, the flow rate could be reduced to $1 / 3$ of the nominal flow until $|S I|>0.5$. When $|S I|>0.5$, then the flow rate must return to the nominal value.

In RMP case, the flow rate could be reduced to $1 / 2$ of the nominal flow, and checked the IS in regular periods of $15 \mathrm{~min}$. If $|S I|>0.5$, one must increase the flow rate by $10 \%$ until the nominal flow is reached, or otherwise reduce the flow by the same value.

A BEMS, using a network of direct digital controllers, controls all process presented with specific control strategies described below. In the HVAC system, the control model proposed is based on a real time determination of the environmental variables that optimize the energy consumption, bearing in mind the regulation and the aim. In the PS, an expedite approach to the control model was elaborated using variable flow rate operation.

\section{Characterization of Case Study}

According to a case study analysis of energy consumption during the year 2006, the total of electrical energy was 1,580 MWh/year and natural gas was $223,799 \mathrm{~m}^{3}$ [7]. The HVAC system and PS can be estimated an average electric power of $58 \mathrm{~kW}$ and 69 $\mathrm{kW}$, respectively, corresponding to $70 \%$ of electricity consumption.
The building under analysis is a sports complex with $15,200 \mathrm{~m}^{2}$ which incorporates an OP (Olympic pool) of $50 \times 25 \mathrm{~m}^{2}$, a CP (children pool) of $25 \times 12.5 \mathrm{~m}^{2}$ and a multi-sports pavilion of $30 \times 50 \mathrm{~m}^{2}$.

\subsection{HVAC System}

The HVAC at pool level is ensured by AHU (air handling units) with dehumidifying and heating capacities in the continuing work. The use of the AHU is necessary to maintain the air quality and the comfort conditions. The most important objective of control is to minimize the high evaporation rates which ask for electric energy for dehumidifying, and which are the largest source of energy losses (Fig. 2).

The latent load associated with the pool evaporation is the most important variable of the process. Therefore, its estimation should be as rigorous as possible. The process of water evaporation occurs because of heat absorbed by the pool water, which causes the water temperature to drop. Thus, the more vapour there is, the more the water is cooled and more heating is required to maintain the comfort level.

The fundamental variable to quantify is the mass of evaporated water $\left(m_{e}\right)$. Recent studies $[14,15]$ identify an empirical formula that takes into consideration the environmental control variables and the users influence. This influence is exerted on the free surface of the water, increasing the area of water in the pool by the movements of the occupants and the number of exposed wetted bodies $N$ :

$$
m_{e}=A_{\text {pool }}\left[0.113-0.0000175 \times A_{\text {pool }} / n_{o}+0.000059\left(\left.P_{s}\right|_{T_{W}}-\left.P_{a}\right|_{T a m b}\right)\right]
$$

The correlation shall be valid only when:

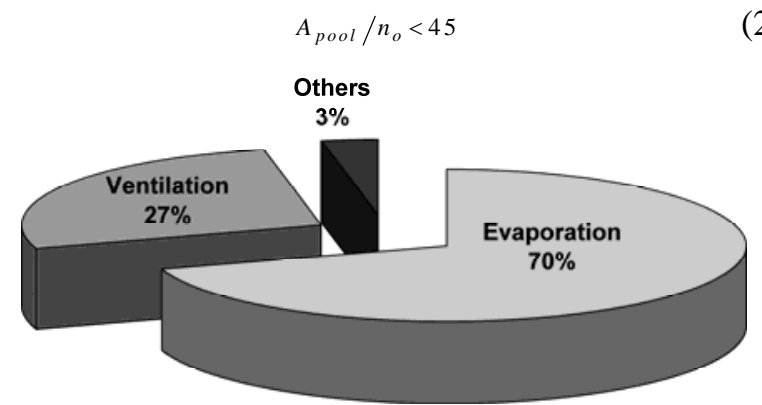

Fig. 2 ISP HVAC energy balance. 
Heat losses by water evaporation are calculated knowing $m_{e}$ and the latent heat of vaporization $\left(L_{v}\right)$, at ambient temperature:

$$
Q_{e}=m_{e} \times L_{v}
$$

The $L_{v}$ is calculated by the empirical formula of Regnault [16], in a range of temperatures between $0{ }^{\circ} \mathrm{C}$ and $200{ }^{\circ} \mathrm{C}$, with an accuracy of $0.02 \%$ :

$$
L_{v}=705.62-0.81 t
$$

The heat losses by water evaporation are calculated according to the expression:

$$
\begin{aligned}
& Q_{e}=A_{\text {pool }} \times \\
& \times\left[0.113-0.000079 \times A_{\text {pool }} / n_{o}+0.000059\left(\left.P_{s}\right|_{T_{w}}-\left.P_{a}\right|_{T_{a m b}}\right)\right] \times \\
& \times\left(705.62-0.81 \times\left(T_{\text {amb }}-273.15\right)\right)
\end{aligned}
$$

The saturated water vapour partial pressure at the water temperature $P_{w}$ is a function of absolute temperature and is given by Ref. [17]:

$$
\left.P_{s}\right|_{T_{w}}=e^{\left(a_{1} \cdot T_{w}{ }^{-1}+a_{2}+a_{3} \cdot T_{w}{ }^{1}+a_{4} \cdot T_{w}{ }^{2}+a_{5} \cdot T_{w}{ }^{3}+a_{6} \cdot \ln \left(T_{w}\right)\right)}
$$

where:

$$
\begin{array}{ll}
a_{1}=-5.8002206 \times 10^{3}, & a_{2}=1.3914993, \quad a_{3}=-4.8640239 \times 10^{-2}, \\
a_{4}=4.1764768 \times 10^{-5}, & a_{5}=-1.4452093 \times 10^{-8} \quad \text { and } \\
a_{6}=6.5459673 . &
\end{array}
$$

The water vapour partial pressure at the air temperature $P_{a}$ is given by Ref. [17]:

$$
\begin{aligned}
& \left.P_{a}\right|_{T_{a m b}}=\left.P_{s}\right|_{T_{a m b}} \times \phi / 100= \\
& ={ }_{\phi \times e}\left(a_{1} \cdot T_{a m b}{ }^{-1}+a_{2}+a_{3} \cdot T_{a m b}{ }^{1}+a_{4} \cdot T_{a m b}{ }^{2}+a_{5} \cdot T_{a m b}{ }^{3}+a_{6} \cdot \ln \left(T_{a m b}\right)\right) / 100
\end{aligned}
$$

Taking into account the complexity of the parameters involved in HVAC systems, the common use of BTS programs is actually the best way to quantify the benefits that can be obtained from the use of different control strategies [18] either from economical or time consuming perspectives.

These BTS programs deal with three main groups of variables, endorsing an ensemble of parameters that influence the building thermal performance [19, 20]. Climatic variables: temperature, relative humidity, solar radiation, wind speed and direction, etc.. Design variables: internal geometry, thermo-physical properties of the materials, HVAC systems, passive and active solar systems, etc.. Use and occupancy variables: routines, internal thermal loads, equipment gains, etc..

There are several BTS programs used in research centers around the world, including in Portugal, such as ESP-r; ENERGYPLUS; TRNSYS and DOE, among others. ESP-r is an integrated modelling tool for the simulation of the thermal, visual and acoustic performance of buildings and the assessment of the energy use and gas emissions associated with the environmental control systems and building materials [21, 22]. The ESP-r program was used in the case study building (Fig. 3), with aim to analyze the energy consumption [23].

The energy consumed in the building and the tank can be modelled by the sum of three major energy losses associated with the pool: losses through the envelope $\left(Q_{e n v}\right)$, losses associated with the water heating introduced into the process $\left(Q_{\text {evap }}\right)$ and the energy required to reduce the building latent thermal load $\left(Q_{\text {lat }}\right)$ through dehumidifying. The first two come from natural gas and the latest from electricity.

The heat exchanges through the building envelope to the environment are quantified by simulation with ESP-r. This energy is supplied by the HVAC system using hot water produced by a natural gas boiler. The thermal power $P_{\text {sen }}$ is obtained by simulation which includes the air renewals recommended by air quality requirements [23, 24]:

$$
Q_{\text {env }}=\left(n \times P_{\text {sen }}\right) /\left(\eta_{c} \times 1,000\right)
$$

Losses associated with the energy used for water heating that is necessary to compensate evaporation are calculated according to the amount of water evaporated

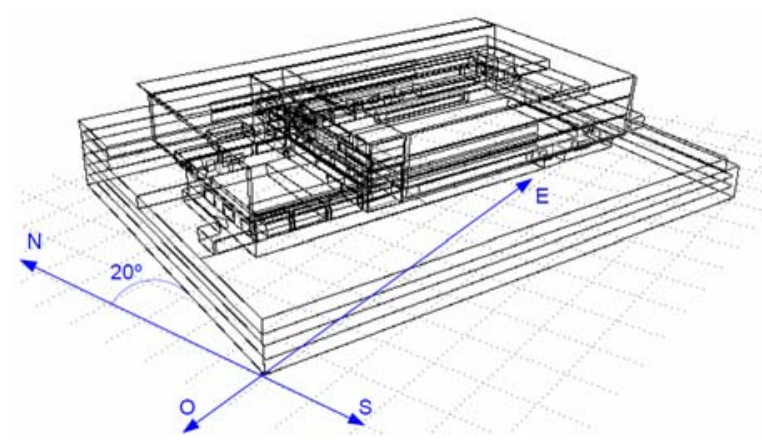

Fig. 3 Model of the building case study. 
in each simulation. This hot water is provided by a hydraulic system coupled to a natural gas boiler.

$$
Q_{\text {evap }}=\left[n \times c_{p} \times m_{e} \times\left(T_{w}-T_{w s}\right)\right] / 1,000
$$

The energy used to reduce the latent load of the building is quantified by simulation with Esp-r. This energy is ensured by the dehumidifier of the HVAC system using electricity:

$$
Q_{\text {lat }}=\left(n \times P_{\text {lat }}\right) /(C O P \times 1,000)
$$

A rigorous choice of environmental variables ( $t_{\mathrm{a}}$-air temperature and $\mathrm{RH}$ ) reduce the evaporation of pool and decrease energy consumption $[25,26]$. The ESP-r simulation gives the latent energy $\left(P_{l a t}\right)$ needed to maintain the $\phi$ level. People can determine the electric power $\left(P_{\text {ep_lat }}\right)$ spend knowing the HVAC coefficient of performance ( $C O P$ ) by:

$$
P_{e p_{-} l a t}=\frac{P_{\text {lat }}}{\text { COP }}
$$

\subsection{Pumping System}

The OP and CP PS are composed by five and three centrifugal pumps in parallel with a nominal water flow rate of have $650 \mathrm{~m}^{3} / \mathrm{h}$ and $188 \mathrm{~m}^{3} / \mathrm{h}$, respectively, and pool water treatment equipments.

The introduction of variable-speed drive in hydraulic systems is current practice in systems with variable flow rate promoting significant reductions in energy consumption [27, 28].

With water quality monitored, it is possible to identify patterns of operation at a variable flow rate, which could provide significant energy savings. The flow rate of the installation can be reduced in the following situations: during the night and in periods when electrical energy costs are high (peak). If water quality begins to deteriorate should be increased gradually the flow rate of the installation until ensure satisfactory conditions of SI. In this situation, variable flow becomes feasible, as well as the installation of VSD to control the flow rate.

The operation patterns at variable flow rates are depending on the number of pumps in use on the system ( $n$ ) and the number of pumps with variable speed $(f)$, which provide significant electricity savings [29].

\section{Results}

In the HVAC, the electric power used to reduce the latent load of the building is quantified by simulation. Three simulations (real, CT and RMP case) were performed considering the respective environmental variables (Table 1).

For the PS, the conditions are strongly dependent on the quality of water determined by the SI, but in this case assuming that $|S I|$ is always less than 0.5 . Applying the expedite formula developed by the author is possible to determine the $(n, f)$ which minimizes the installation electric power (Figs. 4-7) with the flow rate considered (Table 2).

Table 1 HVAC environmental variable.

\begin{tabular}{lllllll}
\hline \multirow{2}{*}{ Variable } & \multicolumn{7}{c}{ OP } & \multicolumn{5}{c}{ CP } \\
\cline { 2 - 7 } & Real & CT & RMP & Real & CT & RMP \\
\hline$t_{\mathrm{a}}\left({ }^{\circ} \mathrm{C}\right)$ & 28.3 & 23.5 & 26.7 & 30.5 & 25.5 & 28.9 \\
$\mathrm{RH}(\%)$ & 52.3 & 80 & 60 & 52.7 & 80 & 60 \\
$\overline{P_{\text {ep_lat }}}(\mathrm{kW})$ & 22.2 & 10.08 & 18.38 & 3.84 & 1.83 & 3.6 \\
\hline
\end{tabular}

Table 2 PS's flow rate and electric power demand.

\begin{tabular}{lllll}
\hline & OP & \multicolumn{3}{c}{$\mathrm{CP}$} \\
\hline & $\mathrm{m}^{3} / \mathrm{h}$ & $\mathrm{kW}$ & $\mathrm{m}^{3} / \mathrm{h}$ & $\mathrm{kW}$ \\
\hline Real & 650 & 46.40 & 188 & 9.96 \\
CT & 216 & 22.05 & 62 & 4.90 \\
RMP & 325 & 33.15 & 94 & 8.90 \\
\hline
\end{tabular}

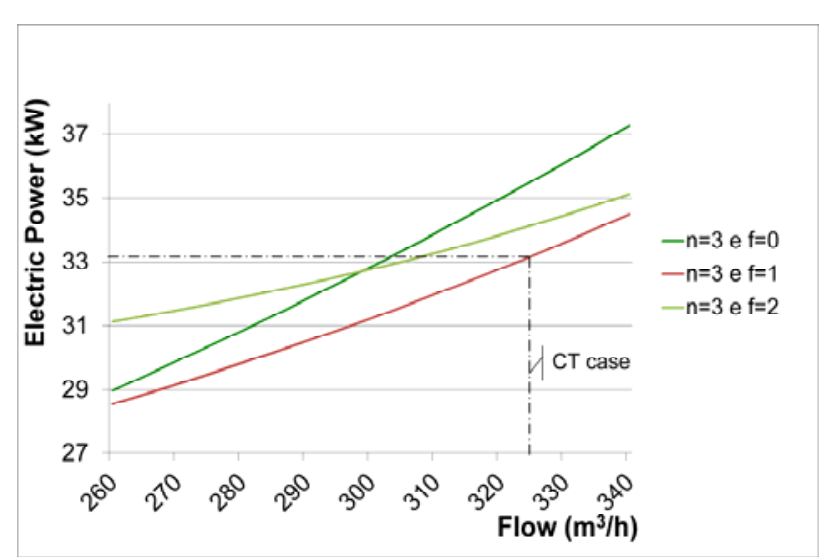

Fig. 4 OP-CT case. 


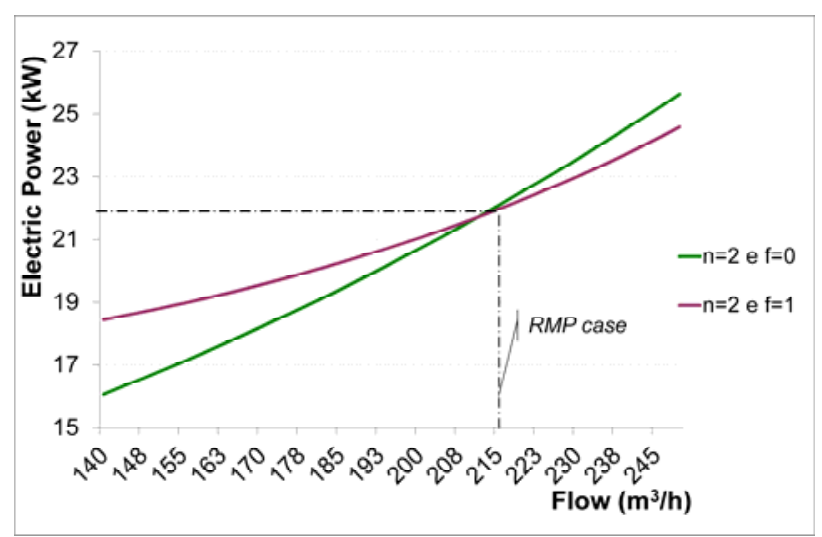

Fig. 5 OP-RMP case.

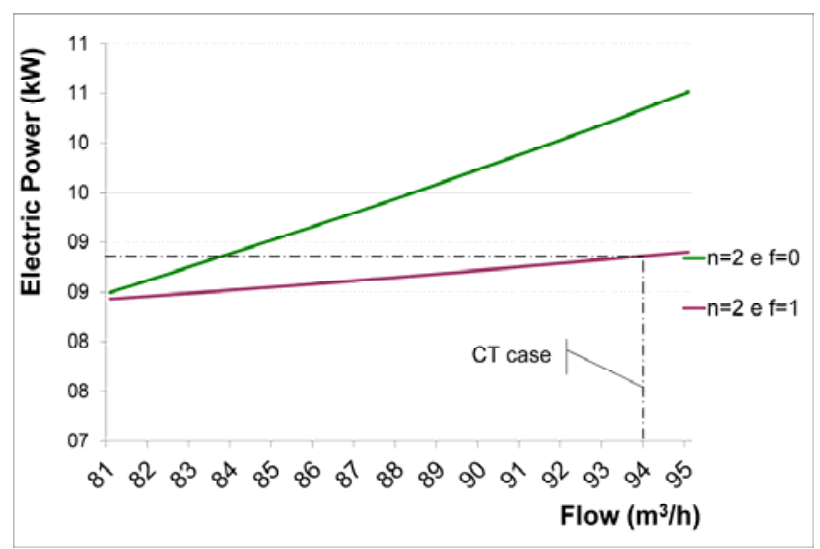

Fig. 2 CP-CT case.

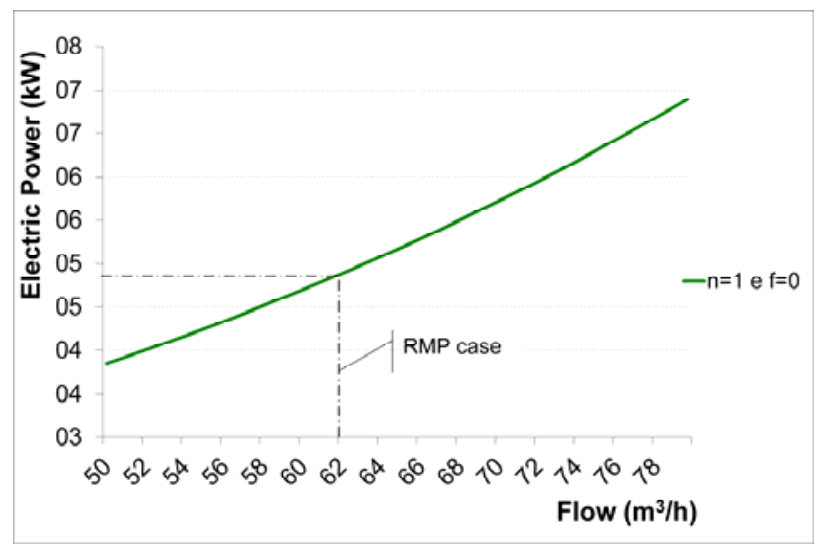

Fig. 7 CP-RMP case.

Table 3 Potential power reduction $(\mathrm{kW})$.

\begin{tabular}{lrrll}
\hline \multicolumn{3}{c}{ HVAC } & \multicolumn{3}{l}{ PS } \\
\hline CT & 14.13 & $24.5 \%$ & 29.41 & $42.9 \%$ \\
RMP & 4.06 & $7.0 \%$ & 14.3 & $20.9 \%$ \\
\hline
\end{tabular}

For HVAC and PS, the results for the power reduction potentials are determined and presented in Table 3.

It is remarkable the enormous reduction of power demand in the case of PS and the substantial decrease in HVAC.

\section{Conclusions}

According to the present results the potential for application of DR concept in this pool is important.

The BEMS designed by the author's implements some control strategies applied to HAVC system and PS to reduce electricity demand during peak hours, which represents a significant reduction in the power demand of $7.0 \%$ and $20.9 \%$ in the HVAC system and the PS system, respectively. In a situation of emergency to the grid, the maximum reduction in power demand that can be obtained is $24.5 \%$ and 42.9\% in HVAC and PS, respectively.

It is expected a promising future for DR in these kinds of buildings taking into account the large number of such sport complexes in Portugal.

The authors believe that the present contribution underlines the importance of sport complexes with indoor swimming pools for contract-based DR, of using adapted building energy management system.

This work has been partially supported by FCT under project grant PEst-C/EEI/UI0308/2011.

\section{References}

[1] DIRECTIVE 2006/32/EC-Energy end-use efficiency and energy services, Official Journal of the European Union, European Community, 2006.

[2] R.M. Lazzarin, G.A. Longo, Comparison of heat recovery systems in public indoor swimming pools, Appl. Therm. Eng. 16 (7) (1994) 561-570.

[3] L. Johansson, L. Westerlund, Energy savings in indoor swimming pools: Comparison between different heat-recovery systems, Appl. Energ. 70 (1994) 281-303.

[4] J.C. Lam, W.W. Chan, Life cycle energy cost analysis of heat pump application for hotel swimming pools, Energ. Convers. Manage. 42 (2001) 1299-1306.

[5] W.L. Lee, C.K. Kung, Optimization of heat pump system in indoor swimming pool using particle swarm algorithm, Appl. Therm. Eng. 28 (2008) 1647-1653.

[6] Smart Grids Task force-Expert Group 3: Roles and Responsibilities of Actors Involved in the Smart Grids Deployment, European Community, 2011.

[7] T. Jacopo, G. Mohamed, L. Matthew, Demand response experience in Europe: Policies, programmes and 
implementation, Energy 35 (4) (2010) 1575-1583.

[8] P. Rodrigues, HAVC Indoor Swimming Pools-Energetic Efficiency, Technical report, 2007.

[9] Portuguese Institute of Quality, 2009, NP EN 15288-1:2009—Swimming pools, Part 1: Safety Requirements for Design.

[10] W. Langelier, The analytical control of anti-corrosion water treatment, Journal AWWA 28 (10) (1936) 1500-1521.

[11] P. Perkins, Swimming Pools, Taylor \& Francis e-Library, UK, 2000.

[12] Inspection and Maintenance of Swimming Pools and Spa Pools in South Australia, South Australian Health Commission, Department of Human Services, South Australian Government, 1992.

[13] Swimming Pool and Spa Manual and Operator's Course, Department of Health and Human Services, Nebraska Government, 2005.

[14] F. Asdrubali, A scale model to evaluate water evaporation from indoor swimming pools, Energy and Buildings 41 (2009) 311-319.

[15] M. Shah, Prediction of evaporation from occupied indoor swimming pools, Energy and Buildings 35 (2003) 707-713.

[16] P. Donald, P.E. Gatley, 2004. Psychrometric chart celebrates 100th anniversary, ASHRAE Journal [Online]. Published Online: Apr. 21, 2004, pp. 16-20, http://bookstore.ashrae.biz/journal/download.php?file=22 915gatley.pdf (accessed Apr. 21, 2010).

[17] H.S. Ren, 2004. Construction of a generalized psychrometric chart for different pressures, J Mech Eng Edu [Online]. Published Online: March 18, 2009, http://www.manchesteruniversitypress.co.uk/uploads/doc s/s3_13.pdf (accessed March 18, 2009).

[18] A. Pedrini, Integration of Low Energy Strategies to the Early Stages of Design Process of Office Buildings in Warm Climate, Universidad de Queensland, Australia, 2003.

[19] J.A. Clarke, Environmental Systems Performance,
University of Strathclyde, UK, 1997.

[20] J.A. Clarke, Energy Simulation in Building Design, 2nd ed., Butterworth-Heinemann, Oxford, 2001.

[21] Energy Systems Research Unit, The ESP-r System for Building Energy Simulation: User Guide Version 10 Series [Online], University of Strathclyde, 2002, http://www.esru.strath.ac.uk/Documents/ESP-r_userguide .pdf (accessed Apr. 3, 2008).

[22] Energy Systems Research Unit, ESP-r Overview [Online], University of Strathclyde, UK, 2004, http://www.esru.strath.ac.uk/Programs/ESP-r_overview.h tm (accessed Apr. 3, 2009).

[23] H. Lacerda, Prevision of Indoor Swimming Pools Thermal Performance, Technical report, University of Coimbra, Portugal, 2007.

[24] Portugues Law No79, de 4 de Abril de 2006, Ministry of Public Works, Transport and Communications Works, Regulation of Climate Energy Systems in Buildings (RSECE) 2006.

[25] E. Ribeiro, H. Jorge, D. Quintela, Indoor swimming pools HVAC system energy optimization, in: PCEEE-Conference in Portugal for an Energy Efficient Economy, 2010.

[26] E. Ribeiro, H. Jorge, D. Quintela, HVAC system energy optimization in indoor swimming pools, in: 3rd International Youth Conference on Energetic, Leiria, 2011.

[27] M. Izquierdo, J. Jiménez, A. Sol, Matlab Software to Determine the Saving in Parallel Pumps Optimal Operation Systems, by Using Variable Speed, IEEE Energy 2030, 2008.

[28] A. Akayleh, A. Mohammed, A. Essam, A. Salah, Water pumping system with PLC and frequency control, Journal of Mechanical and Industrial Engineering 3 (3) (2009) 216-221.

[29] E. Ribeiro, H. Jorge, D. Quintela, The introduction of the VSD in indoor swimming pools pumping, in: PCEEE-Conference in Portugal for an Energy Efficient Economy, 2010. 